\title{
BETWEEN THE TRANSFER OF DEVELOPMENT RIGHTS AND THE EQUIVALENCY VALUES: THE CASE STUDY OF NATAL, BRAZIL
}

\author{
P. ITALO DOS SANTOS GALVÃO \\ Federal University of Rio Grande do Norte, Brazil.
}

\begin{abstract}
Rethinking the way to distribute goods and services in the view of the Rights of the City and the Transfer of Development Rights requires the analysis of the original premise of equivalency values and rights at Transfer of Development Rights (TDR), as well as how cities that adopt urban plans as rule have reached this role. The right to build through the principle of equivalence values serves as an appropriate guide for the rights to build transacted. That is this equivalence is based on the importance of equalizing the values per square meter between the sending and receiving zones. The main objective of this paper is to demonstrate what parameter values should be considered in the transaction of TDR and how this contributes to the rights of the city. Specifically, this work aims to understand which methods of values should be considered in land management and to demonstrate the impact of inequality in the distribution of goods and services in unplanned urban areas in the face of such a transfer, taking as a case study of city of Natal, Brazil. The methodology follows the qualitative method based through bibliographical documents, legislative revisions and quantitative data from Natal. As a result, problems arise around the differences in values between the prices in urban land management in the various areas of the city. Working with equivalence criteria with TDR is an arduous task for many cities, whether in Brazil and abroad. Keywords: development, environment, floor area ratio, land management, quality of life, right to the city, technology, transferable of development right, urban strategies.
\end{abstract}

\section{INTRODUCTION}

Among the multiplicities of urban space, to understand the interaction between urban law and regional urban planning in the current social context makes us rethink urban planning regulations, especially in the use of Property Law in relation to urban space management. The regulations of Urban Law, until now, are advancing toward a greater and better understanding of the Social Function of the Property and not just the property as an economic asset. With this, what was once seen as an exclusive right (and almost 'sacred') evolved to incorporate this social role, i.e. implementing social interests.

One of the urban instruments of this new phase is called the Transfer of Development Rights - or TDR, thus becoming one of the answers to such regulations incorporated into urban planning. In this sense, there is still a field of study and research that aims not only to explain this instrument, but especially to expand its assessment in order to signal the effectiveness in the light of urban management.

The TDR is a tool that is being used in several cities in Brazil and abroad, as a way to expand the capacity for public investment without necessarily invoking the powers of expropriation, i.e. without financially burdening the public purse. The basis of the concept is the disruption of the right to build on a portion of private or public land combined with a guarantee 
to the owner to the use of building potential elsewhere - a sort of financial and economic compensation.

Thereby, the TDR rejects the traditional assumption that property means full mastery of private land. Instead, the concept is based on the idea that property is only a 'bundle of rights' that is not necessarily tied to a unique piece of property. As a result of this transfer of values and rights, the municipality can place restrictions on land use by the owner in preference of public interest projects, as long as established at urban legislations and specific zoning areas.

The goals will be achieved in the chapters of this paper, firstly structured in the importance of recognizing the Transfer of Development Rights and conceptual issues. The second part is based on the principle of equivalence values in TDR, bringing understanding the assessment methods of property in Brazil and what should be considered in the search for sustainable cities and social justice, and finally, it will show the case study of Natal.

\section{THE TRANSFER OF DEVELOPMENT RIGHT: CONCEPTUAL ISSUES}

In urban terms, in North American cities since the 1970s, the Transfer of Development Rights has been used to compensate the land transformation of rural to urban (loss of agricultural potential), or in highway projects and in the preservation of historic buildings. These more or less complex models depend on the state to practice transfer in the US, but most relativize the transfer by weightings in price per square meter of the land or allowed number of real estate buildings. [5]

In its features, the TDR instrument allows the owner of a particular property (land or building) to donate or dispose in part or in whole of the potential levied on their property, and bind this property to a social order. When such public purpose cannot be achieved at the site, the government allows their transfer to another part of town as compensation for this owner.

In these cases there is an interlocutory transfer - the same owner exercises the right to build in another location, and intersubjective transfer - the owner disposes of another or donates to another constructive potential incident in their property. So the original purpose of the instrument was possible with the preservation of historical and environmental areas. In Brazil, some municipalities - before the City Statute (Federal Law 10,257/2001) - have inserted the TDR in its legislation, such as Natal and Porto Alegre in 1994 and Belo Horizonte in 1996.

\section{THE PRIVATE'S PROPERTY VALUE AND THE PRINCIPLE OF EQUIVALENCE VALUES IN TDR}

The construction potential boundary is related to the basic floor area ratio, whose limit may also be a denominated natural area. With this, the urban property owner (private or public) needs a higher limit to build their property. There may be an additional right to build, which belongs to the government. Because of this extension is going to appear adrift space (air rights) with a limit denominated maximum floor area ratio. On closer examination, realizing that the natural area is intrinsically linked to the property, the right to build above the basic limit belongs to society.

However, there are parameters imposed by Brazilian law, for example, the city statute establishes in article 28, paragraph 3 is not enough respect to the limit of maximum floor area ratio, within this extension to the right to build, it must be taken into consideration the available infrastructure to support urban density that the use of adrift space provokes.

Insofar as the level of the basic land use has the premise of an equalization of rights according to the letter of Embu, one must search for just distribution of burdens and benefits generated by the urbanization. This principle is buoyed by the general guidelines by the Law 
$10.257 / 2001$. In contrast, the ceiling occasioned by the result of adrift space is conditional on the carrying capacity and density of a certain area or delimited area in order to protect environmental, cultural, and historical assets of the city landscape.

In fact, the interest of the private sector emerges as the key factor from the moment that the marketing of adrift space occurs and the value of real estate, which is in 'game' over the passing of constructive potential. Doubts persist, even for applicators of the instrument, how to get the desired calculation and it does not generate an imbalance in the distribution between public and private sectors.

With this, assuming that rethinking the way to distribute goods and services to the rights of the city from TDR also requires analysis of the original premise based on the equalization of values in TDR, in how the Brazilian cities that adopt the master plan and urban development rule has reached this role.

The right to build through the principle of equivalence values serves as a guide for amount of the property transacted. That is, this equivalence is based on the importance of equalizing the values per square meter between the sending and receive area.

Problems arise around the differences in values between the urban land prices in different regions of the city. To work with equivalence criteria in the transaction of the right to build, it is a difficult task for many Brazilian cities. This is because the misapplication of the urban instrument in question provokes benefits and burdens of urban goods and services to some over others.

With these initial fundamentals, the City Statute and several master plans in Brazil provide the principle of equivalence values in order to avoid reducing the significant value and disproportionate increase in the transfer of the right to build where the value per square meter is high and low.

Hypothetically, assume that, at the origin of the indexes to be transferred, the land is worth 100 value units per square meter and that one wants to take them to a region where the value is 200 value units per square meter. Admittedly even if any developer wants to transfer the rates of 100 square meters (affected area that suffered the operation). If there was no adjustment, the right would be acquired for 10,000 value units $(\$ 100 \times 100$ square meter $)$ and could be materialized at a value of 20,000 units value $(\$ 200 \times 100$ square meter $)$ an unjustified wealth increment. In equivalence, the land of origin suffers applying a coefficient of 0.5 that adjusts the final value. It turns out that the source of 100 square meter are multiplied by the equivalence factor, i.e. 100 square meter $\times 0.5=50$ square meter and can be materialized in the destination without any increment value. Then 50 square meter $\times \$ 200=\$ 10,000$ at destination $=\$ 10,000$ paid at the origin. [11]

Differently, in the city of Belo Horizonte, Decree n. 9.616 of 1998 regulates the instrument of TDR and provides the equivalence between values per square meter of the sending and received property and it should be based on the Square Meter Values Plant of Land and through the tax laws. [8]

Later this decree was repealed by Decree n. 15.254 of 04 July 2013 and in regard to equivalency values are laid down in Article 4 that in cases where the basic floor area ratio differ according to the category of use liable to installation in the property, the higher value of the urban parameter as a reference for the calculation of TDR will be adopted. [9]

From this viewpoint it is interesting to notice that in Belo Horizonte City has as reference the permeable area and does not use the basic floor area ratio of higher value in order to balance the amount to be transferred. This means that there is the lack of a parameter to establish a balance of values through indicators in TDR in Brazil, taking controversial points. 
In this sense, a related question for discussion is how to evaluate the right to build as part of any development plan of TDR? The purpose of this text does not involve an attempt to estimate or calibrate these values; this is largely a moot point.

The value of sales to be adopted is a controversial topic: some argue for the use of more generic indicators, such as the market value of property or a percentage of this value in order to facilitate this procedure. Others conclude that the adoption of general criteria can lead to a decrease in sales value since the market values are admittedly lower than those charged by the real estate market, defending an analysis in each case. Others still intend to achieve general criteria from values practiced by the real estate market, but this stumbles, with the specific differences of each property, as well as the need for a permanent and responsive monitoring of the functioning of this market. Regardless of the adopted criteria, this must be established in a clear and transparent manner in the plan, leaving no scope for negotiation. [10]

In Brazil, there are several methods; however, what is the best method that should be considered in property value when applying the TDR? Could we consider a single method in TDR in different zoning? The Brazilian Association of Technical Standards (ABNT) by NBR 14653-2: 2004 provides for the evaluation of urban property presenting two methods and their various subdivisions, namely, methods to identify the value of an asset, its fruits and rights (direct comparative method of market data, involution method, the income method, evolutionary method) and methods for the cost of a property (method of quantification of cost and direct comparative cost method). [1]

Direct comparative method of market data identifies the market value of the property by means of technical criteria applied to attributes of comparable elements that comprise a given sample. While the involution method identifies the market value of the asset, based on its efficient use, based on a study model of technical and economic feasibility, through hypothetical compatible undertaking with the property's characteristics and the market conditions in which it is inserted, feasible scenarios for the implementation and commercialization of the product must be considered. The evolutionary method identifies the value of the asset by the sum of the values of its components. If the intent is to determine the market value, the market factor should be considered. The method of income capitalization identifies the value of the asset, based on capitalization present, and its expected net income, considering feasible scenarios.

The methods to identify cost use the direct comparative cost method that identifies the cost of goods by means of technical criteria applied to attributes of comparable elements that comprise a given sample and the cost quantification method that identifies the cost of a property or parts through synthetic or analytical budgets based on the quantity of services and respective direct and indirect costs.

Of all of these, the most common method in the Brazilian real estate market is the comparative model; the method is considered more generic. However, when it used in urban instruments of land regulation, such as the TDR, differences arise about how to apply these methods, especially when we recognize that the universe of urban planning law has several peculiarities.

In this sense, factors relating to the nature of the property, the purpose of the TDR, availability, quality and quantity of information collected on the market in different zoning in the production and reproduction of the city, shows us that is not possible, in principle, to adopt a general theory.

This is because, like many cities in the world, each city has its own features in relation to the forms of urban development. In Brazil, every city space is marked by its economic 
heterogeneity, social and legal, which means that this urban contrast causes growth gaps and supply of goods and services to citizens, i.e. cities are fragmented, poor, unequal and segregated.

In fact, to elucidate the principles and methods of property valuation for urban properties in general and in relation to the TDR, it also seems clear that the involution method tends to be the most suitable for use, whether in private or public property.

Some residual deductive factors, to consider as essential in the transfer of the right to build, are: (a) the receiving area will be based on its efficient use, based on a study model of technical and economic feasibility; (b) upon hypothetical compatible undertaking with the right characteristics and the market conditions in which it is inserted; (c) considering the viable scenarios for running and marketing the product. (d) At transaction of urbanized areas through real estate development, this method establishes the maximum permissible price of land transaction.

According to Pedro Jorgensen every, TDR assumes, there is batches of origin and batches of building potential destination. The batch of origin is the object of public action. In the destination batch, it is the action for its implementation [7].

Evaluation of the TDR must keep compatibility with the characteristics of the area sending and receiving and local market conditions. These requirements can be applied by the involutive method and thus be regarded as the virtual ground method (hypothetical) valid in the application TDR [6].

Therefore, determining the TDR value affects both the portion size of the receiving area or sending, as the use of land that is intended to be preserved (undeveloped), the distance between the two areas (donor-recipient), the availability of right to use (shortage), the appropriate value of property in the receiving area and the definition of the amount of the TDR to be created in the real estate market is also related to the carrying capacity of the receiving area and the future benefits the owner to transfer will receive for transferring their right to urbanize. Thus, the most appropriate price in TDR will be in the amount of equal distribution these rights and values.

According to Mauricio Garcia, the United States of America (USA) presents itself as one of the propellant countries in the operationalization of the transfer of development rights, mainly in establishing simple evaluative methods based on specialists. [4]

The examples are academic exercises in various parts of the United States by renowned experts. The first in North Kingstown, Rhode Island, in Washington County; the method used for valuation of TDR is premised on the expected density equal to the potential of the area to urbanize between the ratio of the amount of land for commercial and industrial uses.

The second case deals with parameters used by Professor David Mills, from New York City, one of the first to analyze the TDR on theoretical models in 1980. The method applied in this urban instrument, in his understanding, should be optimization, i.e. analyze the redistributive effects of the benefits of TDR, as well as the effects on administrative costs. For Mills it is still possible to work with alternative forms of zoning.

The third example is based on the authors Peter Gordon and James Elliot Moore, both professors at the University of Southern California, Los Angeles, which support the thesis that through the general equilibrium method, you can determine the value of TDR, considering, among other variables of interest, the value of productive activities externalities, transport costs, and the distance between the receiving and sending zone.

Interestingly, Gordon and Moore suggest that values in the conservation area (sending zone) may be smaller than the values assigned to externalities (receiving area). Therefore, the 
ideal solution to the maximization problem can have a double value for the price of TDR and its value and can help mitigate the extraordinary gains and externalities.

The fourth example with the methods of assessments in TDR refers to studies of Theodore Panayotou that part of an environmental analysis of the instrument should consider the areas of environmental protection. He proposed a biodiversity conservation tax on income and land ownership, combining them with an explicit goal: to finance the conservation of biodiversity in the tropics. It is noted that this model assumes that the owner is willing to pay.

The fifth example includes the contributions of Cynthia Nickerson and Lori Lynch, both are professors at the University of Maryland. They address the TDR from the optimization and probability methods, i.e. estimated selling prices as well as a number of scenarios are simulated by restricting the constructive potential of the parcels that are not allowed to be used for conservation. The estimates obtained with this model show that prices from TDR may be low in the medium term, which is influenced by the voluntary nature of the urban instrument.

Within these analyzes it is possible to analyze the economic purpose that the transfer of development right has had and rethink the method to determine the value of TDR. The market value in this way, unlike the methods outlined above based on NBR 14653-2, follows subjectivity levels, mainly the deductive residual (involutive) method; by economic theory, TDR assumes an objective value, i.e. the price most likely it could be obtained within a reasonable time (usually represents the expectations of those involved in TDR).

On the other hand, when law regulates the TDR to grant this right, it establishes a value of such a similar market in which it is expected that the value of property in this transfer corresponds to equal rights to the value of the right to urbanize in the receiving area, within an expected value that does not cause disequilibrium and disproportion in transferability of the constructive potential. [3]

When evaluating the property with rights of TDR or any of the components separately, the evaluator must understand the TDR concept, have a determination that it is real or personal property, understand the principles of applicable assessment, have local knowledge of the functioning of TDR, and apply realistic valuation techniques that reflect the market value.

Thus, the market value in Brazilian regulation is an estimated value of an asset and should match the expected value with the TDR to the receiving area. Here there is a particularity of the urban instrument in question that refers to the right to build to be transferred corresponding to the expectations of the local urbanization. I.e. the equalization of values in the application of TDR are of importance so that there are not imbalances in the distribution of burdens and benefits.

Research in Florida indicates that the market value of TDR does not necessarily reflect the value of the predominant land at the sending or receiving area of constructive potential. Moreover, there is the possibility that partial interest can leave a property with the same highest and best use and the same market value that it had before the TDR. [3]

So the comparative method of market data does not seem to be the most ideal to use in TDR, given that this method assumes that sending and receiving areas must have compatible elements, or similar features and the Brazilian experience shows the operation of the TDR has different impacts in different areas, assigning values differently, according to the economic use.

\section{THE CASE STUDY OF NATAL, BRAZIL}

From the previous readings, we can realize that the principle of equivalence values in TDR takes a redistributive way, in which the focus is to promote a redistribution of rights to build 
between those owners according to local criteria, to ensure equitable way to distribute this form wealth.

From the data provided by SEMURB (Environment and Urbanism Department), it was observed that the building potential to be transferred into five administrative proceedings in the city of Natal - between 2008 and 2011 - was 617,712.23 square meters and of this total a single field represented $80.81 \%$ (449,168.03 square meters), localized in the ZPA (Environmental Protection Area) 01, whose authorization has not generated further transfers.

The rest of the building potential was ceded land in the neighborhood of Capim Macio (80539.00 square meters), involving three owners, and Ponta Negra neighborhood (38,005.20 square meters) in a single part of the land, localized in the ZPA (Environmental Protection Area) 05, the latter with transfers already processed.

Twelve transfers were authorized for a total of 69,205.20 square meters (remaining balance of 548,507.00 square meters) to the neighborhood of Capim Macio (66453.11 square meters), Tirol (572.09 square meters) and Lagoa Nova (2,180.00 square meters), namely Capim Macio was responsible for sending and receiving $96.02 \%$ of the building potential transacted (authorized and transferred) from 2008 to 2011 in Natal.

Importantly, the Capim Macio neighborhood does not have ZPAs (Environmental Protection Area), even in the compacting zone, and the reason for such transfers was based on the interest of the Municipality by land on which occurs drainage projects, with construction catchment ponds.

Whereas at the three parcels of land donated in Capim Macio, it is observed that the gross floor areas of the same amounts to the total 31976.33 square meters while the area allowed to be transferred was 80539.00 square meters, i.e. a coefficient was applied the use of the average for the three land, 2.56. Thereby, creating more adrift space (air rights).

Otherwise, the neighborhood of Capim Macio is not a compacted zoning, according to local legislation, which does not permits the application of the coefficient above the basic (that is 1.2 since the Municipal Law n. 082 of 2007 - Direct Plan). What would be the criteria of potential for increasing in a Term or administrative Protocol?

To resolve such doubt, it was necessary to observe the documentation provided by SEMURB to this case study, in the form of "Terms of expropriation agreement" still open in 2008. The documents are similar in their approach and understanding of the potential transfer, reaching values always above the basic land area by as much a coefficient of 1.8 (in one of them the public prosecutor recommended a decrease to 1.2), due to the acquired owner right, plus an additional constructive potential for possible commercialization loss of building potential, and further order (in percentage) as compensation for the loss of monetary value, i.e. there is a 'cascade' of building potential that falls on the transferors land, expanding its basic potential, even in a non-compacting neighborhood.

The five documents provided are a few variations of this modus operandi adopted by the Municipality of Natal in the processes involving the TDR. In terms of economic compensation, three of the five cases involve - in addition to the authorization of TDR - additional payment of money (in the form of damages), only one of them involves the building potential (although with 1.8 of basic floor area ratio) and the other with a coefficient (1.2 of basic floor area ratio). The resources totaled public payment of 3,074,216.97 Brazilian money.

Still, considering the owners of the three lands that have received potential and compensation in money, if they were to sell the total square meters for others, paying market value (as 
established in the Agreement of Terms) - around R\$ 480.00 in Capim Macio. This would represent an additional gain of $\mathrm{R} \$ 38,658,720.00$ as well as the compensation of money already contained in the agreements. Now, the TDR itself is the legal way to compensate for possible losses, needing no other financial compensation and if there is any, it should be a discount on the total transferred and not sum the two values.

Finally, we believe that building potentials transacted (authorized and transferred) with permission from the Municipality of Natal are not consistent with the best expected effectiveness of the instrument expressed in the City Statute and the Direct Plan by the Law n. 082/07 by act to override damages in money above the basic coefficients in non-compacting areas and the absence of specific legislation to authorize it.

\section{CONCLUSIONS}

The approach of TDR in Brazil does not consider the broader question of equity of consumers in a built area. Instead, the traditional value method passively accepts the transfer of wealth from consumers to the owners and holders of the right to build and deals only with aspects of redistribution of control of land use within these narrow limits. [2]

One of the central issues in the application of TDR refers to the need to equalize values between the property that sends the potential and the one that receives. If such equivalence is not occurring or is not established in the formula, the built area increases the transacted value, depending on the difference of property localization. The formulas of TDR in several master plans and local laws in Brazil bring reference to the relationship VTC/VTR (ratio between sending and receive area).

In fact, one of the solutions to these problems is recommended to use the equivalence method of hypothetical values of consideration regarding land located both in areas directly benefited by the sending area as the receiving areas, using the criterion of virtual ground; both should be developed based on research of average values for land in the region. This method has been working in this paper as involutive method, in which one gets the residual value of the land by deducting from the sales price expected construction costs, financial and profit.

It is recommended to use preferably the Real Estate Transfer Tax (ITBI) as a reference market value. ITBI is charged using rate on the financial transaction at the time of sale based on assessment of market value. The difference for the Municipal Property Tax, in this case, is the largest capacities in ITBI update the values per neighborhood, extracted by the current amount (daily) transactions that should feed the database of City Hall.

As a another propose, cities working with TDR could establish, for example, $\mathrm{CI}=((\mathrm{AT} / \mathrm{AR})$ $-0.01)^{*} \mathrm{AR}$, being IC - correction index, AT - ratio between transferor and basic floor area ratio, and AR - potential area to be transferred. Another possibility is that the specific Law of TDR indicates an equivalence value table created from parameterization between ITBI values for real estate area.

Generally, the transferor value is less than the receiver area due to the lowering of assessed value and the impossibility of extra edificability of property. However, there are cases where the transferors still have assessed value greater than the receiver, for example, as occurred in the case of the buildings in Capim Macio in Natal.

Finally yet importantly, as another result, problems arise around the differences in values between the prices in urban land management in the various areas of the city, such as the case of Natal. Working with equivalence criteria with TDR is an arduous task for many cities, whether in Brazil and abroad. 


\section{REFERENCES}

[1] Associação Brasileira de Normas Técnicas., NBR 14653-2:2004: Avaliação de bens Parte 2: Imóveis urbanos. Rio de Janeiro: ABNT. pp. 9-15, 2004.

[2] Berry, D. \& Steiker, G., An economic analysis of transferable development rights. Natural Resources Journal, 74, 1977.

[3] Danner, J.C., TDR's—great idea but questionable value, The Appraisal Journal; Chicago, 1997.

[4] Garcia, M.L., Análisis Económico Legal de los Permisos Transferibles de Desarrollo. Secretaría de Medio Ambiente y Recursos Naturales. Fevereiro, 2003.

[5] Grau, E.R., Direito Urbano. São Paulo, RT, 1983.

[6] Jorgensen, P.A., Transferência do Direito de Construir vista dos lotes de destino: apenas uma modalidade de aplicação dos recursos da outorga onerosa. Disponível em, available at http://abeiradourbanismo.blogspot.com.br/2008/02/transferencia-do-direito-deconstruir.html (acesso em 10 de dezembro de, 2015).

[7] Jorgensen, Pedro. O Zoneamento Inclusivo e a Outorga Onerosa do Direito de Construir. Disponível em available at http://abeiradourbanismo.blogspot.com.br/2015/07/o-zoneamento-inclusivo-e-outorga.html. Acesso em 10 de dezembro de, 2015.

[8] PREFEITURA DE BELO HORIZONTE, Decreto n. ${ }^{\circ} 9.616$ de, 1998.

[9] PREFEITURA DE BELO HORIZONTE, Decreto $n^{\circ}$ 15.254, de 04 de julho de, 2013.

[10] Rolnik, R., Outorga Onerosa e Transferência do Direito de Construir. Estatuto da Cidade e Reforma Urbana: Novas Perspectivas para as Cidades Brasileiras/ Organizadora Letícia Marques Osorio. Porto Alegre: Sergio Antônio Fabris Editor, p. 209 e 210, 2002.

[11] Uzon, N.C., Lincoln Institute of Land Policy. Transferência do Direito de Construir: A Experiência de Porto Alegre, Brasil, Cambridge, 2013. 